\title{
Primary lung cancer metastatic to the breast: case report of a patient in remission
}

\author{
Câncer de pulmão primário metastático da mama: relato de caso de paciente em remissão
}

Pedro Marchiori Cacilhas' ${ }^{1}$, Kelly Mallmann Silva', Monique Wickert' ${ }^{1}$, Allan Arrieira Azambuja ${ }^{1,2}$

\begin{abstract}
While lung carcinoma is the most common of the malignant tumors, primary lung tumors metastatic to the breast are rare and the prognosis is poor. We report a case of a Brazilian, 65-year-old, black, female patient with no family history of breast or lung cancer. During physical gynecological examination, she presented with a palpable nodule in the outer quadrant of the right breast. Based on X-ray, CT, PET-CT and immunohistochemistry investigation, a diagnosis of primary tumor metastatic lung to breast was made. The patient was referred for setorectomy and bi-lobectomy, combined with chemotherapy. She was in remission from November 2012 until December 2018. Given the poor prognosis related to the disease, the evolution presented is surprising.
\end{abstract}

Keywords: Non-small-cell lung carcinoma; Neoplasm metastasis; Case report; Metastasis to breast.

\begin{abstract}
RESUMO
Embora o carcinoma pulmonar seja o mais comum dos tumores malignos, os tumores primários do pulmão metastáticos da mama são raros e o prognóstico é ruim. Relatamos um caso de uma brasileira, 65 anos, negra, do sexo feminino, sem histórico familiar de câncer de mama ou de pulmão. Durante o exame físico ginecológico, apresentou nódulo palpável no quadrante externo da mama direita. Com base na radiografia, tomografia computadorizada, PET-CT e investigação imunohistoquímica, foi feito o diagnóstico de tumor metastático primário do pulmão à mama. A paciente foi encaminhada para setorectomia e bilobectomia, combinada com quimioterapia. Ela estava em remissão de novembro de 2012 a dezembro de 2018. Dado o mau prognóstico relacionado à doença, a evolução apresentada é surpreendente.
\end{abstract}

Descritores: Carcinoma pulmonar de não pequenas células; Metástase neoplásica; Relato de caso; Metástase da mama.

1. Pontifícia Universidade Católica do Rio Grande do Sul, School of Medicine - porto alegre - Rio Grande do Sul - Brazil.
2. Hospital Mãe de Deus - Porto Alegre - Rio Grande do Sul.

Financial support: none to declare.

Conflicts of interest: The authors declare no conflict of interest relevant to this manuscript.

Correspondence author: Allan Arrier Azambuja. Pontifícia Universidade Católica do Rio Grande do Sul.

Rua Monte Alverne, 380, bairro Chácara das Pedras, Porto Alegre, Brazil. Zip code: 91330-510.

E-mail: alanazambuja@gmail.com

Received on: March 31, 2019 | Accepted on: August 18, 2019.

DOI: 10.5935/2526-8732.20190022 


\section{INTRODUCTION}

Metastases from non-breast malignant neoplasms to the breast are rare and account for approximately 4\% of all malignant breast tumors, affecting patients with an average age of 57.4 years ${ }^{1,2}$. Of the primary tumors most commonly reported as metastasizing to the breast are hematopoietic neoplasms, malignant melanoma, and lung carcinoma ${ }^{1,3,4}$. While lung carcinoma is among the most common of all malignant ftumors ${ }^{5}$ it is an infrequent site of metastatic lesions ${ }^{3}$

The prognosis of patients with metastatic lung cancer to the breast is reserved: over $80 \%$ of diagnosed cases of solid tumor metastatic to the breast die within a year ${ }^{3,4}$

The following case report is of a 65-year-old female patient, an 80 pack-year smoker for 40 years. During a gynecological check-up a lump was detected in the breast and, with further investigation, the patient was diagnosed with primary lung cancer with breast metastases. The case report was evaluated by the ethics and research committee of Mãe de Deus Hospital in Porto Alegre - RS (Brazil) and has been approved under the registration number 14372172014.

\section{CASE REPORT}

Female patient, 65 years old, black, with no family history of breast or lung cancer. Na 80 pack-year smoker for 40 years. During a physical gynecological examination, the patient presented a palpable nodule in the outer quadrant of the right breast. A subsequent mammography showed a $2.5 \mathrm{~cm}$ nodule in outer quadrant of the right breast, BIRADS $=5$. The patient was referred for staging through chest X-ray, which showed $4 \mathrm{~cm}$ nodule in the right lung. Later, a CT scan confirmed a spiculated and infiltrative solid mass measuring $4.3 \times 3.3 \mathrm{~cm}$, with its epicenter in the middle lateral segment, infiltrating the adjacent oblique fissure and invading the anterior basal segment of the lower lobe. To investigate other possible active foci of the disease, a PET-CT was performed (Figure 1), confirming irregular hypermetabolic lesion, measuring $2.7 \mathrm{~cm}$, in the outer quadrant of the right breast and a hypermetabolic lesion, $4.3 \mathrm{~cm}$ in diameter, in the right lower lobe (SUV 11). The patient underwent concurrent setorectomy and bi-lobectomy. Pathologic examination showed a diagnosis of moderately differentiated non-small cell lung cancer, without peritumoral invasion. The immunohistochemical analysis of the breast and lung material is shown in Table 1.

The test used for EGFR and ALK was done by PCR amplification and direct sequencing ${ }^{6}$. The diagnostic conclusion was non-small cell lung cancer metastatic to the breast. Both lesions were resected with free margins. Resected mediastinal lymph nodes were negative for metastatic cells.

The patient received adjuvant chemotherapy, six cycles of carboplatin (AUC 6) and pemetrexed (500mg/ $\mathrm{m}^{2}$ ) (every 21 days)7. Tolerance was excellent, and the maintenance of pemetrexed for six months was proposed8,9. The patient has undergone regular PET-CT examination since the immediate postoperative period and at four-monthly intervals. There is no suspicion of recurrence. The patient is currently only in follow-up, with no evidence of neoplasia (Figure 2).

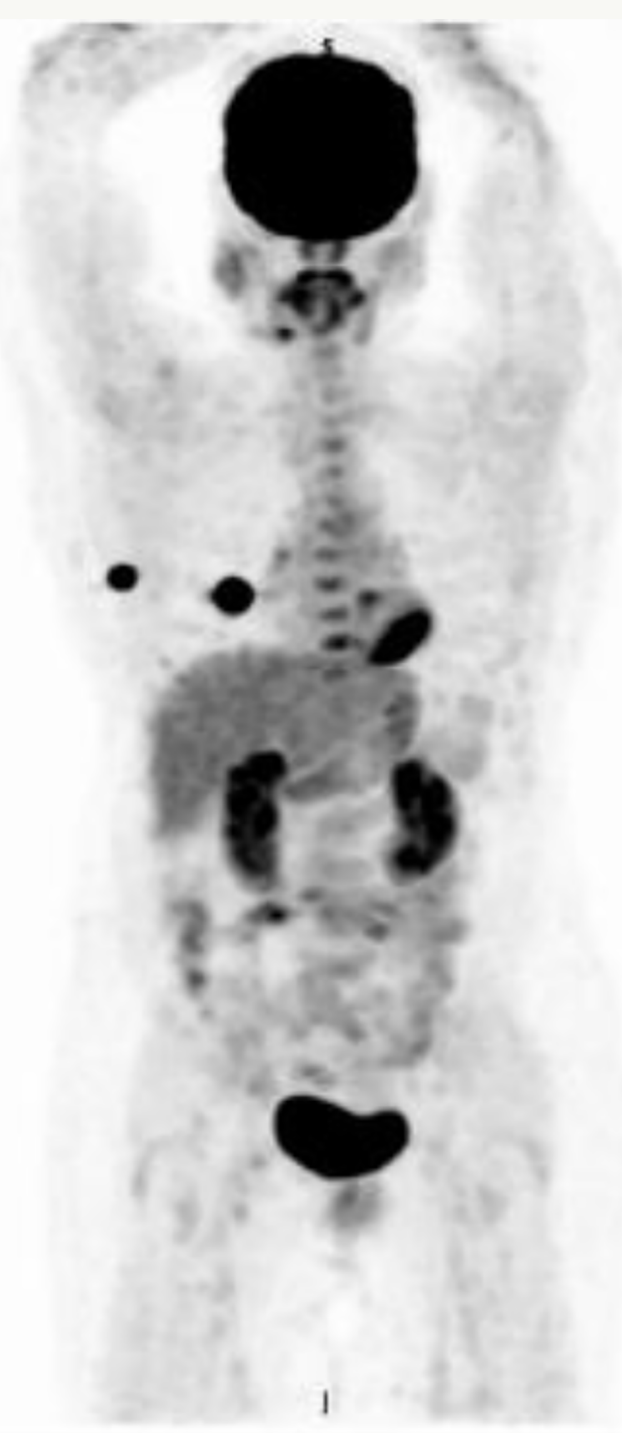

Figure 1. Preoperative PET-CT (17/05/2012) showed lesions in the breast and lung.

\section{DISCUSSION}

Metastases to the breast from other organs are rare, with a prevalence of 1.7 to $6.6 \%$ of breast 
Table 1. Markers of the lesion in the right breast

\begin{tabular}{lcc}
\hline Marker & Positive & Negative \\
\hline TTF-1 & $\mathrm{x}$ & \\
Ki-67 (50\% of cells) & $\mathrm{x}$ & \\
CK7 & $\mathrm{x}$ & \\
AE1 + AE3 & $\mathrm{x}$ & \\
Progesterone receptor (PR) & & $\mathrm{x}$ \\
Estrogen receptor (ER) & & $\mathrm{x}$ \\
BRST-2, GCDFP-15 & & $\mathrm{x}$ \\
C-erbB-2 & & $\mathrm{x}$ \\
CDX-2 & & $\mathrm{x}$ \\
EGFR & & $\mathrm{x}$ \\
ALK & & $\mathrm{x}$ \\
CK20 & & $\mathrm{x}$ \\
\hline
\end{tabular}

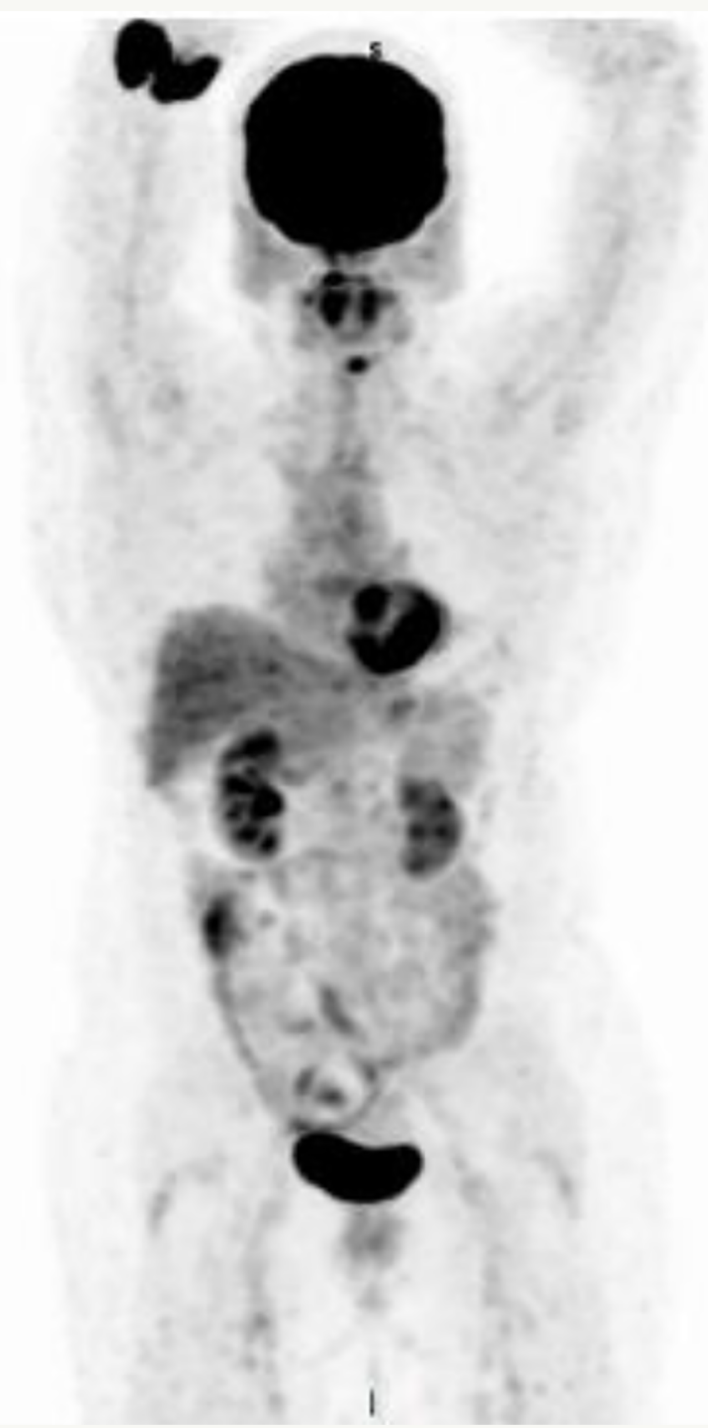

Figure 2. PET-CT conducted 80 months after surgery and chemotherapy. No evidence of recurrence.

tumors. Primary sites that metastasize to the breast are lymphomas, melanomas, lung, ovary, stomach, and more rarely, kidney, liver, pancreatic, pleural and endometrium carcinomas. In children and adolescents, rhabdomyosarcoma is one of the cancers that most metastasize to the breast. In male patients, although rare, a relationship has been shown between this phenomenon and prostate adenocarcinoma. The discovery of a lump in the breast of a patient with a history of cancer may complicate the diagnosis and treatment. Therefore, identifying whether the tumor is primary or metastatic is essential to avoid an unnecessary mastectomy, for example ${ }^{10}$.

Women are five to six times more likely to be affected by metastasis in the breast than men. There are no predisposing factors clearly associated with this condition. While the hormonal issue remains debatable, a higher occurrence of metastasis to the breast is seen in adolescent females and pregnant and lactating women. In men, it is more common in patients undergoing hormone therapy due to prostate cancer. The suggestive mechanism of this phenomenon is that estrogen could increase vascularity and the stromal mass of the breast, which would be a predisposing factor for the development of metastases ${ }^{10}$.

A retrospective study conducted at the Memorial Hospital for Cancer and Allied Diseases evaluated 4000 patients with breast cancer between 1961 and 1970. Fifty-one of whom (1.2\%), 44 women and 7 men, had metastases in the breast. In this study, the primary site that generated most metastases was lymphoma $(n=16)$, followed by melanoma $(n=$ $14)$ and lung carcinoma $(n=6)$. The study revealed that mastectomy did not substantially extend the survival of patients, except in situations where the metastasis was very large and was deeply infiltrated in the breast ${ }^{11}$.

In the study by Surov et al., the radiology center of the Halle-Wittenberg Martin-Luther University enrolled 6,668 patients diagnosed with some metastasis between January 2000 and December 2009. Of whom, 51 had metastasis to breast with primary tumors in extra-mammary sites. The group consisted of 43 women and 8 men with an average age of 61 years. Of the 51 cases of metastasis, the most common primary tumors were melanoma, ovarian, gastric, kidney and sarcoma. Lung cancer, accountted for only $0.89 \%$ of the cases that produced metastasis to the breast $^{12}$.

Clinically, most breast metastases are reported as being fast growing, painless mass with no retraction of the skin or nipple. In Surov's study, metastasis to the breast more often appeared as a solitary nodule than as multiple lesions. Sixty percent $(60 \%)$ of patients with metastatic breast were accidentally diagnosed during staging for the primary cancer, wherein subsequent biopsy confirmed the diagnosis in $70 \%$ of cases. Only $31 \%$ of the patients had a painful solitary nodule or multiple nodules, with or without axillary lymphadenopathy ${ }^{12}$. 
In the reported case, the patient remained asymptomatic and the diagnosis was made during routine clinical examination.

In imaging examinations, the suggestive finding of metastasis to the breast is the presence of one or more rounded nodes in the breast which are difficult to distinguish them from other small nodules, cysts or fibroadenomas. Attention should be paid to metastasis to the breast when there is already another metastasis in a region of soft tissue. Another factor favoring the hypothesis of metastasis is rapid nodular growth between two mammograms. Finally, when the first notable abnormality is increased skin thickness, this may indicate an invasive metastasis via the lymphatic system ${ }^{13}$.

The histological diagnosis of metastasis to the breast is more difficult than the diagnosis of primary breast tumor. In most cases, the definitive diagnosis is made by biopsy. However, biopsy is not always conclusive. In such cases, attention should be paid to the periductal and/or perilobular distribution of malignant cells in the absence of intraductal and/or lobular carcinoma in situ, characteristics which suggest metastasis to the breast originating elsewhere. The role of surgery in the case of metastatic disease should be considered ${ }^{11,14}$.

In addition to histological characteristics, there are various markers that help distinguish breast metastases arising from lung carcinoma and a primary breast tumor. In such cases, immunohistochemistry can be helpful in reaching a correct diagnosis. Thyroid transcription factor-1 (TTF-1) is expressed in $68-80 \%$ of cases of lung adenocarcinoma, while no case report in the literature has reported its presence in breast adenocarcinomas. The marker for estrogen receptor (ER) is rarely responsive in lung cancer (negative in the present case). Finally, mammaglobin is expressed in $48 \%$ to $72 \%$ of breast adenocarcinomas, but is negative in lung adenocarcinomas. Consequently, the use of a panel of markers including ER, PR (progesterone receptor) and mammaglobin is recommended, because none of them is $100 \%$ accurate in distinguishing the primary site of the tumor. Our case represents a typical case of primary tumor in the lung, with ER negative, PR negative, and TTF-1 positive (Table 1). Instead of using the mammaglobin, gross cystic disease fluid protein-15 (GCDFP-15) was used, which is less sensitive but more specific than mammaglobin in identifying primary breast tumors (Table 1$)^{15}$. Some publications attribute to TTF-1 a sensitivity of 93\% for non-small-cell lung tumors (as in our case) and $63 \%$ for others. In primary breast tumors, ER is expressed in $80 \%$ and PR in $60 \%$ of cases. GCDFP-15 is expressed in $45-53 \%$ of breast carcinomas ${ }^{13,14}$.

An EGFR mutation search was considered to test the possibility of adenocarcinoma. ALK gene undergoes rearrangement in $2-7 \%$ of patients with non-small cell lung cancer. Its frequency increases in young and non-smoking patients, and occurs almost exclusively in adenocarcinomas. In a phase I/II study, the use of crizotinib represented a response rate of $61 \%$ in 149 ALK positive patients ${ }^{16}$. The use of crizotinib appears to offer new hope for the positive ALK group, since it has proved to be more beneficial than the previous standard treatment, consisting in the use of carboplatin/cisplatin and pemetrexed $(p<0.0001)^{17}$.

In our case, a mutation search was conducted in the patient, However, both ALK and EGFR were negative, therefore the treatment was not directed towards these targets.

Although malignant metastases to the breast are rare, when a breast tumor is identified it is important to confirm the site of the primary tumor. The importance of identifying and differentiating the primary and secondary sites is necessary to properly direct treatment in order to avoid the patient having to undergo unnecessary and possibly harmful procedures. In the present case, despite the prognosis of patients with metastatic lung cancer to breast be reserved - more than $80 \%$ of diagnosed cases of solid metastatic tumor to the breast die within a year - the patient presented good evolution.

\section{AUTHOR'S CONTRIBUTION}

Pedro Marchiori Cacilhas: Manuscript writing.

Kelly Mallmann Silva: Manuscript writing.
Monique Wickert: Manuscript writing.

Allan Arrier Azambuja: Manuscript writing.

\section{REFERENCES}

1. Georgiannos, S.N., et al., Secondary neoplasms of the breast: a survey of the 20th Century. Cancer, 2001. 92(9): p. 2259-66.

2. Bartella, L., et al., Metastases to the breast revisited: radiological-histopathological correlation. Clin Radiol, 2003. 58(7): p. 524-31.
3. Toombs, B.D. and L. Kalisher, Metastatic disease to the breast: clinical, pathologic, and radiographic features. AJR Am J Roentgenol, 1977. 129(4): p. 673-6.

4. Alvarado Cabrero, I., et al., Metastases to the breast. Eur J Surg Oncol, 2003. 29(10): p. 854-5.

5. [cited 201519 de Maio ]; Available from: http:// www2.inca.gov.br/wps/wcm/connect/tiposdecancer/site/home/pulmao/definicao. 
6. Kimura, H., et al., Detection of epidermal growth factor receptor mutations in serum as a predictor of the response to gefitinib in patients with non-smallcell lung cancer. Clin Cancer Res, 2006. 12(13): p. 3915-21.

7. Herbst, R.S., et al., TRIBUTE: a phase III trial of erlotinib hydrochloride (OSI-774) combined with carboplatin and paclitaxel chemotherapy in advanced non-small-cell lung cancer. J Clin Oncol, 2005. 23(25): p. 5892-9.

8. Belani, C.P., et al., Quality of life in patients with advanced non-small-cell lung cancer given maintenance treatment with pemetrexed versus placebo (H3E-MC-JMEN): results from a randomised, double-blind, phase 3 study. Lancet Oncol, 2012. 13(3): p. 292-9.

9. Paz-Ares, L.G., et al., PARAMOUNT: Final overall survival results of the phase III study of maintenance pemetrexed versus placebo immediately after induction treatment with pemetrexed plus cisplatin for advanced nonsquamous non-small-cell lung cancer. J Clin Oncol, 2013. 31(23): p. 2895-902.

10. Lee, S.H., et al., Metastatic tumors to the breast: mammographic and ultrasonographic findings. J Ultrasound Med, 2000. 19(4): p. 257-62.
11. Hajdu, S.I. and J.A. Urban, Cancers metastatic to the breast. Cancer, 1972. 29(6): p. 1691-6.

12. Surov, A., et al., Metastases to the breast from non-mammary malignancies: primary tumors, prevalence, clinical signs, and radiological features. Acad Radiol, 2011. 18(5): p. 565-74.

13. Ko, K., et al., Micropapillary lung cancer with breast metastasis simulating primary breast cancer due to architectural distortion on images. Korean J Radiol, 2012. 13(2): p. 249-53.

14. Ji, F.F., et al., Contralateral breast metastasis from pulmonary adenocarcinoma: two cases report and literature review. J Thorac Dis, 2012. 4(4): p. 384-9.

15. Bhargava, R., S. Beriwal, and D.J. Dabbs, Mammaglobin vs GCDFP-15: an immunohistologic validation survey for sensitivity and specificity. Am J Clin Pathol, 2007. 127(1): p. 103-13.

16. Camidge, D.R., et al., Activity and safety of crizotinib in patients with ALK-positive non-small-cell lung cancer: updated results from a phase 1 study. Lancet Oncol, 2012. 13(10): p. 1011-9.

17. Kwak, E.L., et al., Anaplastic lymphoma kinase inhibition in non-small-cell lung cancer. N Engl J Med, 2010. 363(18): p. 1693-703. 